\title{
Cambios morfológicos secundarios a material de sutura quirúrgica
}

\section{Morphological changes due to surgical suture material}

\author{
H. Martínez Alcázar ${ }^{1}$ \\ M. Subirana Domènech ${ }^{1}$ \\ G. Font Valsecchi ${ }^{1}$ \\ C. Dasi Martínez ${ }^{2}$ \\ ${ }^{1}$ Médicos Forenses, \\ Servei de Patologia \\ Forense del Institut de \\ Medicina Legal de \\ Catalunya, Barcelona \\ ${ }^{2}$ Facultativo del Servicio \\ de Histopatología del \\ Instituto Nacional de \\ Toxicología y Ciencias \\ Forenses, Barcelona
}

Correspondencia: Helena Martínez Alcázar Servei de Patologia Forense del Institut de Medicina Legal de Catalunya

Edifici G, $5^{\text {a }}$ planta

Ciutat de la Justícia

Gran Via Corts Catalanes, 111

08014 Barcelona

E-mail: helena.martinez@xij. gencat.cat

Fecha de recepción:

08. MAR. 2013

Fecha de aceptación: 24. FEB. 2014

\begin{abstract}
Resumen
Los materiales de sutura pueden ocasionar alteraciones o artefactos que en ocasiones nos plantearán dudas de diagnóstico diferencial con procesos tumorales o de otra naturaleza. Durante la realización de una autopsia el patólogo puede hallar una masa localizada en un órgano, tejido o vaso, que le puede llevar a pensar en un proceso tumoral, y un estudio histopatológico sorprenderlo con el diagnostico de reacción tisular por material de sutura.
\end{abstract}

Palabras clave: Patología forense. Autopsia forense. Material de sutura. Fibrosis gástrica.

\begin{abstract}
Suture materials can cause changes or artefacts that can occasionally raise doubts in the differential diagnosis of tumour processes or of any other nature. During the performance of an autopsy, the forensic pathologist may find a mass in organs, tissues or vessels that may lead him to think about a tumoral process, and the histopathological diagnosis surprise him with tissue reaction caused by suture material.
\end{abstract}

Key words: Forensic pathology. Forensic autopsy. Suture materials. Gastric fibrosis.

\section{Introducción}

Durante una autopsia muchas veces no se dispone de la totalidad de los antecedentes patológicos del fallecido. Por este motivo, algunos hallazgos son de difícil interpretación medicoforense, como sucedió en el que presentamos.

\section{Presentación del caso}

Se trata de un varón de 81 años con antecedentes de hipertensión arterial en tratamiento, hernia inguinal intervenida 20 años antes e hiperplasia benigna de próstata. Tres días antes de su fallecimiento presentó dolor en el epigastrio, por el que consultó a su médico de cabecera y el electrocardiograma se informó como normal. El dolor mejoró, pero a pesar de ello presentó un cuadro de náuseas y síncope, por el que fue atendido por el servicio de emergencias médicas, quienes únicamente pudieron acreditar la muerte.

Durante la autopsia se evidenció una cicatriz de laparotomía media supraumbilical de la que no constaba el motivo en sus antecedentes patológicos, ya que la única intervención documentada era como consecuencia de una hernia inguinal.

La causa de la muerte en este caso fue un hemopericardio secundario a rotura de infarto transmural en la pared libre del ventrículo izquierdo y aterosclerosis coronaria grave de los tres vasos.

Un hallazgo de autopsia que llamó nuestra atención fue la presencia de cambios en la morfología externa del estómago, de aspecto hiperémico, retráctil, con nódulos diseminados y amarillentos (Figuras 1a y 1b). Al corte estos nódulos presentaban un contenido negro y filoso que recordaba pepitas de fruta (Figura 2). 
El estudio histológico llevado a cabo determinó que se trataba de una fibrosis cicatricial evolucionada y calcificada en relación con restos de material de sutura (seda) (Figura 3).

\section{Discusión}

Todo material utilizado durante una intervención quirúrgica se comporta como cuerpo extraño en el organismo y puede producir una reacción tisular dependiendo del tipo de sutura utilizada ${ }^{1}$. De la misma forma se comportan las gasas olvidadas en el organismo durante la intervención, que pueden llegar a simular una tumoración ${ }^{2}$.

Si nos centramos en el material de sutura, las posibles complicaciones son dehiscencias, infecciones, abscesos, granulomas, reacciones alérgicas y adherencias.

En el mecanismo de reabsorción de las suturas intervienen fenómenos proteolíticos y enzimáticos, que pueden experimentar variaciones porque en los pacientes con fiebre, infección o deficiencia proteica el proceso de absorción puede acelerarse ${ }^{1}$.

Consideramos que es de interés para el médico forense conocer tanto los tipos de sutura como sus características $^{3}$, ya que de éstas dependerán las reacciones tisulares visibles durante la autopsia (Tabla 1).

La elección del tipo de material de sutura dependerá no sólo de si se trata de vasos o tejidos, sino de si la sutura es o no reabsorbible ${ }^{4}$; por ejemplo, en el caso de sutura vascular y gastrointestinal es recomendable que sea reabsorbible ${ }^{5,6}$.

El hallazgo durante la autopsia de cambios morfológicos de un órgano, tejido o vaso puede llevar a confusión con nódulos tumorales o metastásicos, y el diagnóstico sólo será exacto si se realiza un estudio histopatológico, como ocurrió en el caso expuesto. La cicatriz de la laparotomía media sugería una intervención quirúrgica previa, pero el aspecto macroscópico del estómago planteaba la duda sobre si se trataba de cambios posquirúrgicos o tumorales.

A la hora de interpretar las posibles implicaciones del material de sutura durante una autopsia debemos tener en cuenta los siguientes hechos de interés en la interpretación medicoforense del hallazgo:

- Puede ocasionar una reacción fibroesclerótica de la pared de un vaso en las anastomosis ${ }^{7}$.

- También puede provocar una reacción granulomatosa crónica secundaria a la sutura no

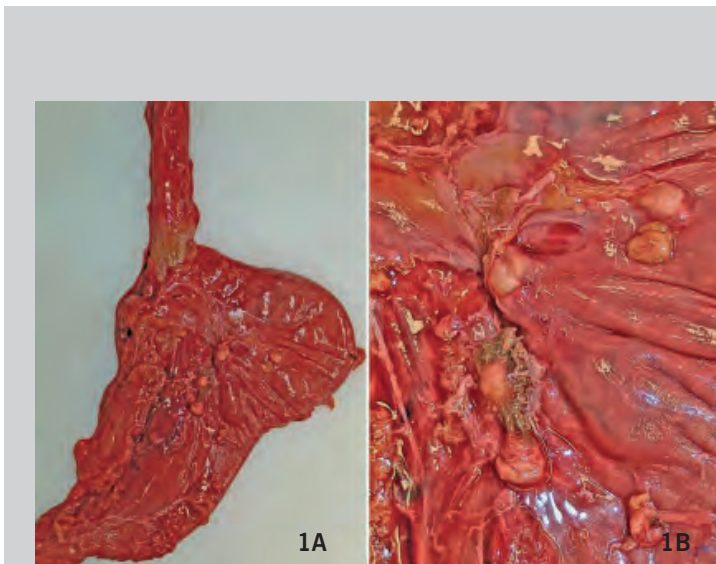

Figura 1.

a) Estómago hiperémico, retráctil y con múltiples nódulos en la pared. b) Imagen macroscópica de uno de los nódulos abierto.

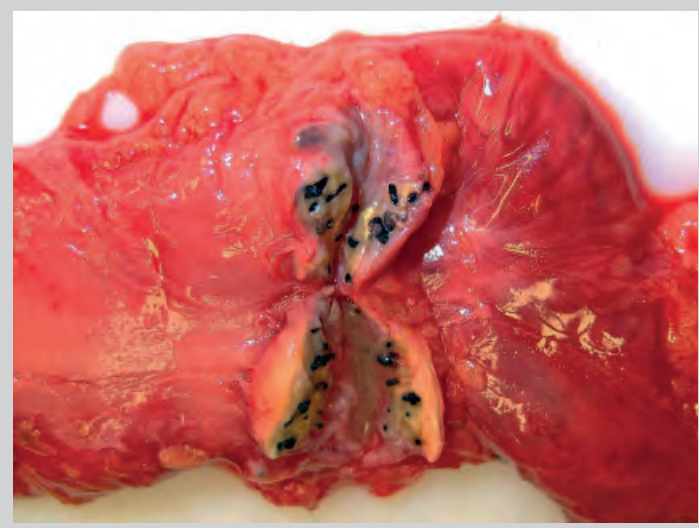

Figura 2.

Imagen de uno de los nódulos seccionado.

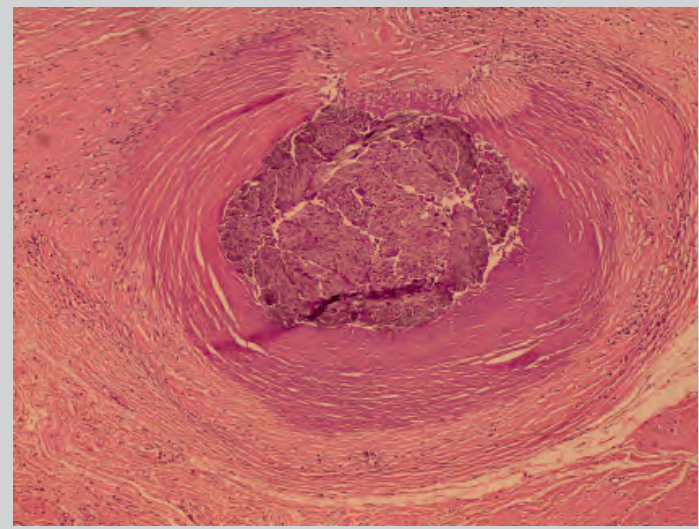

Figura 3.

Material de sutura englobado por tejido fibroso hialinizado (HE 10 x 10 aumentos). 
Tabla 1.

Tipos de sutura, tiempo de reabsorción y reacción tisular (Adaptada de Ribeiro et al.

20054).

\begin{tabular}{|c|c|c|c|c|}
\hline & Características & $\begin{array}{l}\text { Mecanismo } \\
\text { de reabsorción }\end{array}$ & Tiempo de reabsorción & Reacción tisular \\
\hline \multicolumn{5}{|l|}{ Absorbibles } \\
\hline Naturales & & $\begin{array}{l}\text { Proteolítico y } \\
\text { enzimáticos }\end{array}$ & & \\
\hline $\begin{array}{l}\text { Catgut } \\
\text { ( } 98 \% \text { colágeno) } \\
\text { (simple o crómico) }\end{array}$ & $\begin{array}{l}\text { Multifilamento } \\
\text { Resistente } \\
\text { tensión y flexible }\end{array}$ & & 90 días & Moderada \\
\hline Sintéticas & & Hidrólisis & & \\
\hline $\begin{array}{l}\text { Ácido poliglicólico } \\
\text { (Dexon®) }\end{array}$ & Multifilamento & & Total 120 días & Menor reacción \\
\hline $\begin{array}{l}\text { Poliglactina } 910 \\
\text { (Vicryl }(\circledR)\end{array}$ & Multifilamento & & 60 días & Poca \\
\hline $\begin{array}{l}\text { Polidioxanona } \\
\text { (PDSTM) }\end{array}$ & Monofilamento & & $\begin{array}{l}180 \text { días } \\
6 \text { meses }\end{array}$ & Poca \\
\hline Poligliconato & Monofilamento & & 180 días & Poca \\
\hline Poliglecaprona 25 & & & & \\
\hline
\end{tabular}

\section{No reabsorbibles}

\section{Naturales}

Lino algodón y seda

Multifilamento

Más traumático

Más complicaciones

\section{Sintéticas}

Nailon, poliéster

Monofilamento Multifilamento

Acero inoxidable, Multifilamento titanio reabsorbible, como puede ser el caso de la implantación de un marcapasos que altere su funcionamiento ${ }^{8}$.

- La fibrosis posquirúrgica endocárdica, las calcificaciones distróficas, así como el propio material de sutura, constituyen superficies trombogénicas $^{9}$.

- También será útil el hallazgo de una sutura para ayudar a la orientación de la identidad en el caso de cadáveres en mal estado ${ }^{10}$.
Por tanto, el conocimiento de los cambios posquirúrgicos puede ser útil para el médico forense para evitar diagnósticos erróneos, así como para aportar datos de identificación en cadáveres en avanzado estado de putrefacción.

\section{Agradecimientos}

Los autores quieren expresar su más sincero agradecimiento al Sr. Eduardo Aizpun y a los técnicos especialistas en patología forense por su colaboración. 


\section{Bibliografía}

1. Hsiao WC, Young KC, Wang ST, Lin PW. Incisional hernia after laparotomy: randomized comparison between early-absorbable and late-absorbable suture materials. World J Surg. 2000;24:747-51.

2. Onodera $\mathrm{H}$, Furuya $\mathrm{Y}$, Uchida $\mathrm{M}$, Nakayama $\mathrm{H}$, Nakamura H, Sakakibara Y, et al. Intracranial foreign body granuloma caused by dural tenting suture. $\mathrm{Br}$ J Neurosurg. 2011;25(5):652-4.

3. Galindo F. Enciclopedia de cirugía digestiva. Argentina. 2007. (Consultado el 28/02/2013.) Disponible en: http://www.sacd.org.ar/usiete.pdf

4. Ribeiro CM, Silva Júnior VA, Silva Neto JC, Vasconcelos BC. Clinical and histopathological study of tissue reactivity to monofilament suture materials: nylon and poliglecaprone 25 in rats. Acta Cir Bras. 2005;20(4):284-91.

5. Thiede A, Lütjohann K, Beck C, Blunck F. Absorbable and nonabsorbable sutures in microsurgery: standardized comparable studies in rats. J Microsurg. 1979;1(3):216-22.

6. Kostić LL. Sutures in digestive surgery. Acta Chir Iugosl. 1994;(2 Suppl):211-20.

7. Ussia G, Feldmann D, Galletti M, Salerno A, Jacono A, Galletti G. Histopathological aspects of tissue reactivity to suture materials in microsurgical arterial anastomosis. Ital J Surg Sci. 1985;15(3):287-92.

8. Garg N, Moorthy NA. Mysterious pacemaker suture: an uncommon foreign body reaction. Indian Pacing Electrophysiol J. 2011;11(1):27-30.

9. Garfia A, Martínez MC, Repetto F. Evaluación médico-legal de las prótesis intracardíacas en la autopsia: II. Prótesis valvulares. Cuad Med Forense. 2013;(28):61-6.

10. Subirana M, Galtés JI, Jordana X, García C, Malgosa A. Importancia del estudio antropológico forense para la calificación jurídica de una muerte violenta. Cuad Med Forense. 2005;(42):293-305. 